\title{
Post-deposition heat treatment effect on microstructure of suspension plasma sprayed bioactive glass coatings
}

\author{
E. Cañas*, V. Sanz, M.J. Orts, E. Sánchez \\ Instituto de Tecnología Cerámica (ITC), Universitat Jaume I, 12006, Castellón, Spain
}

Eugeni Cañas Recacha

Email: eugeni.canas@itc.uji.es

Vicente Sanz Solana

Email: vicente.sanz@itc.uji.es

María José Orts Tarí

Email: mariajose.orts@itc.uji.es

Enrique Sánchez Vilches

Email: enrique.sanchez@itc.uji.es
Telephone number: (+34) 964342424

Fax number: (+34) 964342425 


\section{Abstract}

This research addresses a simple and easy method to improve the microstructure of suspension plasma sprayed bioactive glass coatings. Based on previous research of the group, a SPS bioactive glass coating was deposited under optimised variables employing a stable suspension feedstock.

After the microstructural characterisation, the coatings were subjected to a heat treatment at 400, 500 and $600{ }^{\circ} \mathrm{C}$ peak temperatures. These temperatures have been chosen according to the shrinkage curve of the working glass which results from a hot stage microscope. Results show an improvement of the coatings microstructure (reduction in both porosity and thickness and increment of the adhesion) after a heat treatment at $500{ }^{\circ} \mathrm{C}$ with respect to the original coating. However, for a temperature of $400{ }^{\circ} \mathrm{C}$ the coating microstructure is not altered (porosity, thickness and adherence are the same as those of the original sample) while at 600 ${ }^{\circ} \mathrm{C}$ the entire coating is completely delaminated.

Keywords: Bioactive glass suspensions; Hot stage microscopy; Suspension plasma spraying; Bioactive glass coatings; Post-deposition treatment 


\section{Introduction}

Plasma spraying represents a technique with great potential to obtain bioactive glass (BG) coatings since it allows the in-situ deposition of the coating while preserving the amorphous nature of the feedstock. For that reason, some research groups have started to work on this technique to obtain and optimise the properties of BG coatings from powders [1-4]. But, as in other feedstocks [5-8], the deposition of particle suspensions employing Suspension Plasma Spraying (SPS) could also provide some advantages in comparison with powder feedstocks. Once the glass suspension has been obtained, the atomisation of the same into the plasma torch is not different from other feedstocks deposited by the SPS process [9-11]. However, during deposition of glass suspensions, care must be taken with the temperature of the substrate surface, since if a high surface temperature is not reached before depositing the coating, melted glass particles develop rapid sintering and cool without splashing when impacting the substrate leading to a first glass layer formed by small spherical glass drops connected between them and high inner porosity [12-14]. After 1-2 spraying passages, the glass layer already deposited, retains more heat from the torch, reaching high surface temperatures (higher than the glass transition temperature) and giving rise to a glass coating with a viscous top layer [15]. From that point, two phenomena take place at the same time. On the one hand, the deposition rate is increased since all arriving particles, including the resolidified ones can be easily stacked to the deposited coating. On the other hand, due to stagnation flow of plasma gases, the arriving particles are deflected parallel to the coating surface, resulting in a mainly columnar coating growth mechanism which gives rise to the formation of a top layer made up of large melted glass agglomerates with a very high number of closed and spherical pores due to gas entrapment because of the viscous flow sintering of the glass $[13,15,16]$. Therefore, a layered and columnar coating is achieved, with very porous microstructure which negatively affects the coating adhesion. 
Fortunately, a simple post-spray treatment can provide great benefits for the BG coatings microstructure together with an enhancement of their adhesion [2]. Post-spray treatments have been widely used in the last decades in order to improve thermal sprayed coatings and increase their final quality. There are several post-treatments depending on both the type of coating material and the final application [17-19]. Typical post-deposition treatments are listed below:

- Heat treatment, which could be taken by different ways (electromagnetic heating by laser, microwave or spark plasma sintering; furnace treatment and combustion flame treatment).

- Impregnation, on which a liquid sealant is used to fill the open porosity by capillarity and then solidifies. Sometimes, a heat treatment is required to homogenize the microstructure.

- Finishing, in order to achieve the desired roughness (by polishing) and dimension (by grinding) based on the final application.

For the case of bioactive glass coatings, taking into account that they are brittle materials and a very carefully temperature control should be taken to avoid undesired crystallisation, a furnace heat treatment appears to be the suitable method to improve the bioglass coatings microstructure since the entire coating is heated in a homogeneous way and the temperature is perfectly controlled. In addition, employing a furnace makes it possible to work with very low temperatures (close to the glass transition temperature). Just care must be paid in order to control the thermal expansion of both the coating and the substrate, as the latter is also heated inside the furnace, and to avoid the formation of undesired crystalline phases.

Thus, the paper highlights the benefits of post-deposition heat treatment for bioactive glass coatings microstructure and properties contributing to the feasibility of the SPS process to produce good quality coatings. 


\section{Experimental}

\subsection{Bioactive glass suspension feedstock}

For the present work, a bioactive glass suspension feedstock was used, that has been already prepared, stabilised and characterised by the authors in previous works [12,13]. Basically, a bioactive glass with an oxide composition (in wt\%) 47.6 $\mathrm{SiO}_{2}-5.3 \mathrm{P}_{2} \mathrm{O}_{5}-23.2 \mathrm{CaO}-24.0 \mathrm{Na}_{2} \mathrm{O}$ was obtained by melting at $1450^{\circ} \mathrm{C}$ the corresponding raw materials mixture and quenching into water, and the resulting frit particles were used to prepare an organic based glass suspension, as described before [12,13], resulting in a suspension with a solids concentration of $10 \mathrm{vol} . \%$ and a narrow particle size distribution with a mean size of $\mathrm{D}_{50}=2.2 \mu \mathrm{m}$.

In those previous works, it was shown that the bioactive glass suspension feedstock exhibited an adequate rheological behaviour to be used as feedstock for SPS. The viscosity curve (Figure 1) showed a pseudoplastic behaviour and low viscosity values when shear was acting which makes it suitable for transport and injection $\left(5.6 \cdot 10^{-3}\right.$ and $5.4 \cdot 10^{-3} \mathrm{~Pa} \cdot \mathrm{s}$ at a shear rate of 127 and $51000 \mathrm{~s}^{-1}$ respectively) into the plasma torch. Besides, no significant variation of viscosity with time (thixotropy) was observed. Concerning the stability, it was shown that for one hour there was no variation in the light transmitted or reflected (as shown in Figure 2), therefore no sedimentation occurred. However, from 15 to 24 hours, an increase of the light reflected in the lower part of the cell $(0-5 \mathrm{~mm})$ can be seen with a decrease in the backscattered light in the upper part $(35-40 \mathrm{~mm})$ due to the sedimentation of coarse glass particles, while the fine particles remain suspended. But this drawback can be solved as authors demonstrated [13]. After 21 days of suspension storage, it was possible to re-disperse it only by simple agitation. The particle size distribution of the suspension after 21 days was measured, and there were no differences between the as-prepared and the re-dispersed suspensions particle sizes. 


\subsection{Sintering treatment of the suspension powders}

In the present work, a thermal characterisation of the feedstock was also performed in order to assess the behaviour of the home-made bioactive glass powders contained in the suspension at high temperatures and, after coatings deposition, to plan their heat treatment to improve coatings microstructure. For that reason, the sintering curve (variation in shrinkage with temperature) of the glass particles was determined by hot stage microscopy (HSM) (MISURA 3, Expert System Solutions, Italy) at a heating rate of $25^{\circ} \mathrm{C} / \mathrm{min}$, in air atmosphere. The HSM is the combination of a heating stage (hot stage) with a sample holder coupled with a light microscope and a system that allows to record the changes in shape and geometry of a sample with temperature when submitted to a thermal cycle. A cylindrical test piece was prepared by pressing the powder obtained after the solvent was removed from the glass suspension and was introduced into the microscope and subjected to the selected heating rate up to the melting of the powder.

\subsection{Coating deposition and characterisation}

The bioactive glass suspension feedstock was sprayed onto metallic substrates by SPS. Although SPS coatings from the same feedstock were already deposited by authors in previous works $[12,13]$, for the present article new coatings were sprayed and characterised with the aim of reproducing the targeted microstructure to be optimised by the subsequent post-spraying process. Previously to deposition, the substrates (AISI 304) were grit-blasted and cleaned. Grit-blasting was performed using black corundum with a pressure of $4.2 \mathrm{~Pa}$, and then the substrates were cleaned with ethanol. Roughness $\left(\mathrm{R}_{\mathrm{a}}\right)$ of grit-blasted and cleaned substrates was measured employing a roughness measurement equipment (HOMMELWERKE T8000, Jenoptik AG, France). The obtained $\mathrm{R}_{\mathrm{a}}$ value was $2.2 \pm 0.1 \mu \mathrm{m}$. 
To enhance the adherence of the final glass coating, substrates were first coated with a bond coat that was deposited from anatase feedstocks (Metco 102, Oerlikon Metco, Switzerland) with a particle size distribution between 10 and $55 \mu \mathrm{m}$ by atmospheric plasma spraying (APS) and using the spraying parameters given by the supplier (Table 1).

The APS facility used comprises a plasma gun (F4-MB, Oerlikon Metco, Switzerland) managed by a six-axis robot (IRB 1400, ABB, Switzerland). In the gun, the plasma generation was accomplished using argon as primary gas and hydrogen as secondary gas. Details about the SPS equipment have been reported in previous works [20, 21].

Finally, bioactive coatings were deposited with the facility described above, preheating the bond coated substrates between $300{ }^{\circ} \mathrm{C}$ and $350{ }^{\circ} \mathrm{C}$. The plasma working gases used were a mixture of argon as primary gas and hydrogen as secondary gas. The spraying conditions utilised in this work are detailed in table 1.

Then, coatings were subjected to a post-treatment in an electric furnace to improve their microstructure. For that purpose, coatings were heated with a rate of $25^{\circ} \mathrm{C} / \mathrm{min}$ (the same used in the HSM step) from room temperature until a maximum temperature, which is selected according to the results of the hot-stage microscope test of the feedstock powder as mentioned in the previous section. Once the maximum temperature was reached, it was kept for 30 minutes and finally the coatings were allowed to cool free in the furnace. Higher dwell times at maximum temperature were discarded since the coating started to present some delaminate.

Polished cross-sections of the coatings, as-sprayed and post-treated, were prepared and subsequently observed in a field-emission gun environmental scanning electron microscope (FEG-ESEM) (QUANTA 200FEG, FEI Company, USA), and their amorphous/crystalline character was determined by X-ray diffraction (XRD) (Advance diffractometer, Bruker Thetatheta, Germany). 
On the other hand, coatings thickness and porosity were estimated by image analysis (MicroImage) at 2000x magnifications from FEG-ESEM pictures following a procedure set out elsewhere [22]. In addition, with aim of confirm the success of the heat treatment, the relative interfacial toughness $\left(\mathrm{K}_{\mathrm{c}}\right)$ was determined in order to qualify the adhesion of the assprayed coating and those treated at $400{ }^{\circ} \mathrm{C}$ and $500{ }^{\circ} \mathrm{C}$. This test was done by Vickers indentation (Hardness tester M1C010, Emco-Test, Austria) on the polished cross-sections of the coatings at the interface between the bond coat and the glass coat [23-26], performing 10 indentations of $5 \mathrm{~N}$ per coating with a diamond pyramid indenter. After each indentation, the half-length of the diagonal and the total length of the cracks (from the centre of the indentation until the end of the crack) generated at the interface were measured and used to calculate a relative interfacial toughness by means of Evan and Wilshaw model [24-26]. 


\section{Results and discussion}

\subsection{Thermal behaviour of suspension powders}

Figure 3 corresponds to the sintering curve of the bioactive glass powder obtained with the hot-stage microscope. This technique allows not only qualitative observations but also quantitative sintering studies [27-30]. The characteristic points or temperatures at which the test piece acquires certain geometries are showed in the same figure. Those characteristic temperatures were first defined by Scholze [31], and then Pascual et al. [32,33], comparing the calculated viscosities of the abovementioned characteristic temperatures with experimental values obtained with a high temperature viscometer.

The sintering curve shows four temperature ranges. From room temperature up to about 500 ${ }^{\circ} \mathrm{C}$ thermal expansion controls the size of the test piece and shrinkage slightly decreases. At $500{ }^{\circ} \mathrm{C}$ glass sintering starts. At this temperature glass viscosity is low enough to allow densification and shrinkage to occur. In the temperature range $650-900{ }^{\circ} \mathrm{C}$ a plateau is observed due to devitrification [4, 34]. Crystal formation increases viscosity and sintering stops. Two main phases are formed: a sodium calcium silicate and a sodium calcium phosphate $[4,35,36]$. At $900{ }^{\circ} \mathrm{C}$ sintering restarts and shrinkage slowly starts up to $1050{ }^{\circ} \mathrm{C}$. At this point, it can be appreciated the expansion of the cylindrical sample, which contrasts to the literature [4,34-36]. This unusual effect is caused by the entrapped air, which is hardly released to the ambient during the heat treatment due to the very fine porosity associated with the fine glass particle size. However, after all the air is removed, the shrinkage restarts again and takes place very fast until viscosity is low enough for the test piece to lose its original cylindrical shape. The temperatures at which shrinkage starts and stops slightly vary depending on the starting particle size of the glass in the test piece [4], and on the heating rate [30].

This curve is important as it allows to define temperatures at which the glass can be treated to be annealed or to modify the topography of a glass coated substrate. 


\subsection{Bioactive glass coatings}

The suspension prepared was used to obtain coatings by SPS with the spraying parameters detailed in table 1, which were optimised in an experiment grid described in a previous paper [13]. The microstructure of the coatings has been also thoroughly described in that previous research [13], and revealed two different zones, as can be seen in Figure 4, where each zone has been delimited. The inner part of the coating, just above the bond-coat, was a highly porous continuous layer of $35 \mu \mathrm{m}$ built by an assembly of fine droplets partially sintered with high open porosity (marked with white arrows). The external part of the coating had a completely different appearance as it consisted of dispersed and densified areas whose crosssection indicates that a higher degree of densification than that of the inner part of the coating has been achieved. This can be due to the fact that when spraying the last glass droplets impinge onto a hotter surface than that of the first ones. However, the coating microstructure is not optimal as it would have been convenient to have a more regular surface, uniformly covered by densified areas, instead of isolated dense areas over a highly porous layer, that probably weakly bonds to the substrate.

A first approach to improve the microstructure of the coatings was to modify the spraying conditions and to highly preheat the bond coated substrate but no significant changes were observed within the operational range of those parameters in the APS facility used.

\subsection{Post-spray heat treatment}

According to the literature [2] a post-deposition heat treatment could be needed when the microstructure of the coating is highly porous or not adequate. In order to do so, the thermal schedule must be carefully designed so that the coatings porosity could be reduced avoiding crystallization and without altering the substrate. 
A decrease in porosity could be only accomplished if a considerable amount of liquid phase is formed. There are two temperature ranges in which liquid phase develops as stated in the sintering curve obtained with the hot-stage microscope (figure 3). The first one goes from 500 ${ }^{\circ} \mathrm{C}$ to $620{ }^{\circ} \mathrm{C}$ and corresponds to the rapid increase of shrinkage up to the plateau where sintering stops due to crystallization. The onset of the second temperature range in which liquid phase develops and another step of shrinkage occurs begins at about $900{ }^{\circ} \mathrm{C}$. Nevertheless, this last temperature range was discarded as it was too high to be withstood by the substrate.

The coatings were thermally treated at three temperatures around the first sintering step: 400, 500 and $600{ }^{\circ} \mathrm{C}$, following the firing cycle set out in section 2.3. Coatings deposition and characterisation.

The coating treated at $600{ }^{\circ} \mathrm{C}$ was detached from the substrate probably due to a thermal mismatch between substrate and coating. Thus, this temperature was found to be too high for the substrate used and no higher temperatures were tried.

Figure 5 shows the polished cross-sections of the coatings treated at $400{ }^{\circ} \mathrm{C}$ and $500{ }^{\circ} \mathrm{C}$. The microstructure of the $400{ }^{\circ} \mathrm{C}$ treated coating shows no difference with the microstructure of the original coating (figure 4): a porous layer near the substrate and isolated glass areas over this layer. Nevertheless, the coating treated at $500{ }^{\circ} \mathrm{C}$ showed an improved microstructure compared to the original one. The porous layer was densified, and the coating has become a homogeneous layer over the substrate.

Percentage of porosity and mean thickness of the coatings were determined by image analysis coupled to the scanning electron microscope, and results are shown in figure 6 . As it can be seen the coating treated at $400{ }^{\circ} \mathrm{C}$ has the same porosity, thickness and adherence than the original one. For the $500{ }^{\circ} \mathrm{C}$ treated coating, percentage of porosity and mean thickness decrease due to sintering during the heat treatment. 
Figure 6 also includes the relative interfacial toughness values determined by means of Evans and Wilshaw model from Vickers indentations. The common procedure consists in applying several indentations at different loads, to estimate a critical load from which the toughness is calculated [23]. Nevertheless, due to the low quality of glass microstructure as well as the poor mechanical resistance of glass layer the calculation of this parameter has been carried out by using only one load of $5 \mathrm{~N}$ (following the procedure described in section 2.3. Coatings deposition and characterisation), in which visible cracks through the glass layer-bond coat interface could be monitored. Similar procedure has been also followed in previous research $[24,25]$. It can be appreciated that; an increment of the interfacial toughness takes place for the $500{ }^{\circ} \mathrm{C}$ treated coating with regard to the as-sprayed coating and that treated at $400{ }^{\circ} \mathrm{C}$, since a more homogeneous coating microstructure is achieved at $500{ }^{\circ} \mathrm{C}$ due to the liquid phase developed.

In addition, two examples of the indentation traces for the as-sprayed coating and that treated at $500{ }^{\circ} \mathrm{C}$ are presented in figure 7 . For better understanding, in figures $7 \mathrm{~b}$ and $7 \mathrm{~d}$ both indenter trace and crack were surrounded in red. As demonstrated in figure 6, the coating treated at $500{ }^{\circ} \mathrm{C}$ shows higher fracture toughness, and this is supported by figure $7 \mathrm{c}$, at which a lower penetration of the indenter and shorter interfacial cracks can be appreciated, while for the as-sprayed coating, a greater penetration of the indenter can be appreciated, and longer and wider cracks, which confirms the low adherence of this coating. Nevertheless, in both cases there is a little deviation of the indenter from the bond coat to the glass coat, due to the difference in hardness of both layers.

Finally, figure 8 shows the XRD pattern of the original coating and the post-treated one at 500 ${ }^{\circ} \mathrm{C}$. Both patterns correspond to fully amorphous materials. Thus, the post-treatment at $500{ }^{\circ} \mathrm{C}$ preserves the amorphous structure without any devitrifying phase occurring during the firing schedule. 


\section{Conclusions}

A bioactive glass suspension was prepared to be used as a feedstock in a SPS process. The rheological behaviour of this suspension was adequate and showed low viscosity values when shear was acting. The stability of the suspension was assessed as no sedimentation was detected for 15 hours. Both characteristics made the suspension suitable for transport and injection into the plasma torch.

Bioactive coatings were obtained through the deposition of the feedstock suspension by SPS, based on previous research. The coatings were amorphous and showed a porous and cracked microstructure, made up of two different zones, as reported elsewhere. Even for the most suitable spraying conditions, the resulting coating was highly porous and irregular. In order to improve the microstructure of the coatings thermal post-treatments were designed according to the sintering curve of the powder feedstock obtained in a hot-stage microscope. The aim of the post treatment was to generate enough liquid phase to partially sinter the glass coating without developing crystalline phases and without altering the substrate.

Heat treatment at a peak temperature of $500{ }^{\circ} \mathrm{C}$ significantly improved the microstructure partially sintering the coating, homogenizing its thickness and improving adherence. XRD confirmed that the amorphous nature of the coating was preserved during the thermal treatment.

By carefully designing the firing schedule, according to the shrinkage curve obtained with a heating microscope, it is possible to improve the microstructure of a bioactive glass coating without neither changing its amorphous nature nor altering the substrate.

\section{Acknowledgements}

The authors of the present work thank Universitat Jaume I of Castellón the support provided in funding RECUBIO project (P1-1B2013-69) and action 3.1. of the Research Promotion 
Plan (PREDOC/2015/50) as well as Prof. Rodrigo Moreno (ICV-CSIC, Madrid, Spain) for his kindly contribution in the rheological characterisation. 


\section{References}

[1] G. Goller, The effect of bond coat on mechanical properties of plasma sprayed bioglasstitanium coatings, Ceram. Int. 30 (2004) 351-355.

[2] V. Cannillo, A. Sola, Different approaches to produce coatings with bioactive glasses: Enamelling vs plasma spraying, J. Eur. Ceram. Soc. 30 (2010) 2031-2039.

[3] M. Monsalve, H. Ageorges, E. Lopez, F. Vargas, F. Bolivar, Bioactivity and mechanical properties of plasma-sprayed coatings of bioglass powders, Surf. Coat. Technol. 220 (2013) 60-66.

[4] E. Cañas, M. Vicent, E. Bannier, P. Carpio, M.J. Orts, E. Sánchez, Effect of particle size on processing of bioactive glass powder for atmospheric plasma spraying, J. Eur. Ceram. Soc. 36 (2016) 837-845.

[5] C. Monterrubio-Badillo, H. Ageorges, T. Chartier, J.F. Coudert, P. Fauchais, Preparation of $\mathrm{LaMnO}_{3}$ perovskite thin films by suspension plasma spraying for SOFC cathodes, Surf. Coat. Technol. 200 (2006) 3743-3756.

[6] F.L. Toma, G. Bertrand, S. Begin, C. Meunier, O. Barres, D. Klein, C. Coddet, Microstructure and environmental functionalities of $\mathrm{TiO}_{2}$-supported photocatalysts obtained by suspension plasma spraying, App. Catal. B: Environ. 68 (2006) 74-84.

[7] H. Kassner, R. Siegert, D. Hathiramani, R. Vassen, D. Stoever, Application of suspension plasma spraying (SPS) for manufacture of ceramic coatings, J. Therm. Spray Technol. 17 (2008) 115-123.

[8] A. Killinger, R. Gadow, G. Mauer, A. Guignard, R. Vassen, D. Stöver, Review of new developments in suspension and solution precursor thermal spray processes, J. Therm. Spray Technol. 20 (2011) 677-695.

[9] J. Fazilleau, C. Delbos, V. Rat, J.F. Coudert, P. Fauchais, B. Pateyron, Phenomena involved in suspension plasma spraying part 1: suspension injection and behaviour, Plasma Chem. Plasma Process. 26 (2006) 371-391.

[10] L. Pawlowski, Suspension and solution thermal spray coatings, Surf. Coat. Technol. 203 (2009) 2807-2829.

[11] P. Sokolowski, S. Kozerski, L. Pawlowski, A. Ambroziak, The key process parameters influencing formation of columnar microstructure in suspension plasma sprayed zirconia coatings, Surf. Coat. Technol. 260 (2014) 97-106.

[12] E. Cañas, M. Vicent. M.J. Orts, R. Moreno. E. Sánchez, Bioactive glass suspensions preparation for suspension plasma spraying, J. Eur. Ceram. Soc. 36 (2016) 4281-4290.

[13] E. Cañas, M. Vicent, M.J. Orts, E. Sánchez, Bioactive glass coatings by suspension plasma spraying from glycolether-based solvent feedstock, Surf. Coat. Technol. 318 (2017) 190-197.

[14] A. Cattini, L. Latka, D. Bellucci, G. Bolelli, A. Sola, L. Lusvarghi, L. Pawlowski, V. Cannillo, Suspension plasma sprayed bioactive glass coatings: Effects of processing on 
microstructure, mechanical properties and in-vitro behaviour, Surf. Coat. Technol. 220 (2013) 52-59.

[15] G. Bolelli, D. Bellucci, V. Cannillo, R. Gadow, A. Killinger, L. Lusvarghi, P. Müller, A. Sola, Comparison between suspension plasma sprayed and high velocity suspension flame sprayed bioactive coatings, Surf. Coat. Technol. 280 (2015) 232-249.

[16] D. Bellucci, G. Bolelli, V. Cannillo, R. Gadow, A. Killinger, L. Lusvarghi, A. Sola, N. Stiegler, High velocity suspension flame sprayed (HVSFS) potassium-based bioactive glass coatings with and without $\mathrm{TiO}_{2}$ bond coat, Surf. Coat. Technol. 206 (2012) 38573868 .

[17] L. Pawlowski, The Science and Engineering of Thermal Spray Coatings (second ed.), John Wiley \& Sons, Great Britain (2008)

[18] Y. Yang, K.H. Kim, J.L. Ong, A review on calcium phosphate coatings produced using a sputtering process - an alternative to plasma spraying, Biomater. 26 (2005) 327-337.

[19] H. Pokhmurska, B. Wielage, T. Lampke, T. Grund, M. Student, N. Chervinska, Posttreatment of thermal spray coatings on magnesium, Surf. Coat. Technol. 202 (2008) $4515-4524$.

[20] M. Vicent, E. Bannier, P. Carpio, E. Rayón, R. Benavente, M.D. Salvador, E. Sánchez, Effect of the initial particle size distribution on the properties of suspension plasma sprayed $\mathrm{Al}_{2} \mathrm{O}_{3}-\mathrm{TiO}_{2}$ coatings, Surf. Coat. Technol. 268 (2015) 209-215.

[21] P. Carpio, E. Bannier, M.D. Salvador, A. Borrell, R. Moreno, E. Sánchez, Effect of particle size distribution of suspension feedstock on the microstructure and mechanical properties of suspension plasma spraying YSZ coatings, Surf. Coat. Technol. 268 (2015) 293-297.

[22] V. Carnicer, M.J. Orts, R. Moreno, E. Sánchez, Microstructure assessment of suspension plasma spraying coatings from multicomponent submicronic $\mathrm{Y}$ $\mathrm{TZP} / \mathrm{Al}_{2} \mathrm{O}_{3} / \mathrm{SiC}$ particles, Ceram. Inter. 44 (2018) 12014-12020.

[23] G. Marot, J. Lesage, Ph. Démarécaux, M. Hadad, St. Siegmann, M.H. Staia, Interfacial indentation and shear tests to determine the adhesion of thermal spray coatings, Surf. Coat. Technol. 201 (2006) 2080-2085.

[24] A.N. Khan, J. Lu, H. Liao, Heat treatment of thermal barrier coatings, Mat. Eng. A 359 (2003) 129-136.

[25] S.A. Sadeghi-Fadaki, K. Zangeneh-Madar, Z. Valefi, The adhesion strength and indentation toughness of plasma-sprayed yttria stabilized zirconia coatings, Surf. Coat. Technol, 204 (2010) 2136-2141.

[26] A.G. Evans, T.R. Wilshaw, Quasi-static solid particle damage in brittle solids-I. Observations, analysis and implications, Acta Metall. 24 (1976) 939-956.

[27] A.R. Bocaccini, B. Hamman. Review: in situ high-temperature optical microscopy. J. Mater. Sci. 34 (1999) 5419- 5436.

[28] C. Siligardi, M.C. D’Arrigo, C. Leonelli, Sintering behaviour of glass-ceramic frits, Am. Ceram. Soc. Bull. 79 (2000) 88-92. 
[29] C. Lara, M.J. Pascual, M.O. Prado, A. Durán, Sintering of glasses in the system RO$\mathrm{Al}_{2} \mathrm{O}_{3}-\mathrm{BaO}-\mathrm{SiO}_{2}(\mathrm{R}=\mathrm{Ca}, \mathrm{Mg}, \mathrm{Zn})$ studied by hot-stage microscopy, Solid State Ion. 170 (2004) 201-208.

[30] O. Bretcanu, X. Chatzistavrou, K. Paraskevopoulos, R. Conradt, I. Thompson, A.R. Boccaccini, Sintering and crystallisation of 45S5 Bioglass ${ }^{\circledR}$ powder, J. Eur. Ceram. Soc. 29 (2009) 3299-3306.

[31] H. Scholze, Influence of viscosity and surface tension on Hot Stage Microscopy measurements on glasses, Ber. Dtsch. Keram. Ges. 391 (1962) 63-68

[32] M.J. Pascual, L. Pascual, A. Duran, Determination of the viscosity-temperature curve for glasses on the basis of fixed viscosity points determined by hot stage microscopy, Phys. Chem. Glasses 42 (2001) 61-66.

[33] M.J. Pascual, A. Durán, M.O. Prado, A new method for determining fixed viscosity point of glasses, Phys. Chem. Glasses 46 (2005) 512-520.

[34] J.R. Jones, A.G. Clare, Bio-Glasses: An introduction (first ed.), John Wiley \& Sons, Great Britain (2012).

[35] L. Lefebvre, L. Gremillard, J. Chevalier, R. Zenati, D. Bernache-Assolant, Sintering behaviour of 45S5 bioactive glass, Acta Biomater. 4 (2008) 1894-1903.

[36] N.A. Zarifah, W.F. Lim, K.A. Matori, H.A.A. Sidek, Z.A. Wahab, N. Zainuddin, M.A. Salleh, B.N. Fadilah, A.N. Fauzana, An elucidating study on physical and structural properties of $45 \mathrm{~S} 5$ glass at different sintering temperatures. J. Non-Crystal. Solid. 412 (2015) 24-29. 
Table 1 Plasma spraying parameters used

Spraying parameters $\mathrm{TiO}_{2}$ bond coat

(APS)

38

14

600

120

1000

Spraying distance (mm)

Spraying velocity $\left(\mathrm{mm} \mathrm{s}^{-1}\right)$
Bioactive glass top layer

(SPS)

37

8

700

*Standard litres per minute 


\section{Figure Captions}

Figure 1. Viscosity curve of the suspension feedstock

Figure 2. Stability of the suspension. a) Transmittance and b) Backscattering

Figure 3. a) Sintering curve of the BG suspension powder from the HSM with the image of the test piece at each characteristic temperature and b) Diagram expansion for the temperature range comprised between $350-650^{\circ} \mathrm{C}$.

Figure 4. Microstructure of the as-sprayed coating before the heat treatment. a) Surface, b) cross-section and c) cross-section at higher magnification showing the two different zones of the coating

Figure 5. Cross-sections of the coating after the heat treatment. a) and b) coating treated at $\left.400{ }^{\circ} \mathrm{C}, \mathrm{c}\right)$ and d) coating treated at $500^{\circ} \mathrm{C}$

Figure 6. a) Mean thickness, b) porosity and c) adherence of the as-sprayed coating and the coatings treated at 400 and $500{ }^{\circ} \mathrm{C}$

Figure 7. Coatings micrographs (BS detector: A-B mode) showing the interfacial indentations. a), b) As-sprayed coating and c), d) treated at $500{ }^{\circ} \mathrm{C}$

Figure 8. XRD patterns of the as-sprayed coating [13] and the coating treated at $500{ }^{\circ} \mathrm{C}$ 


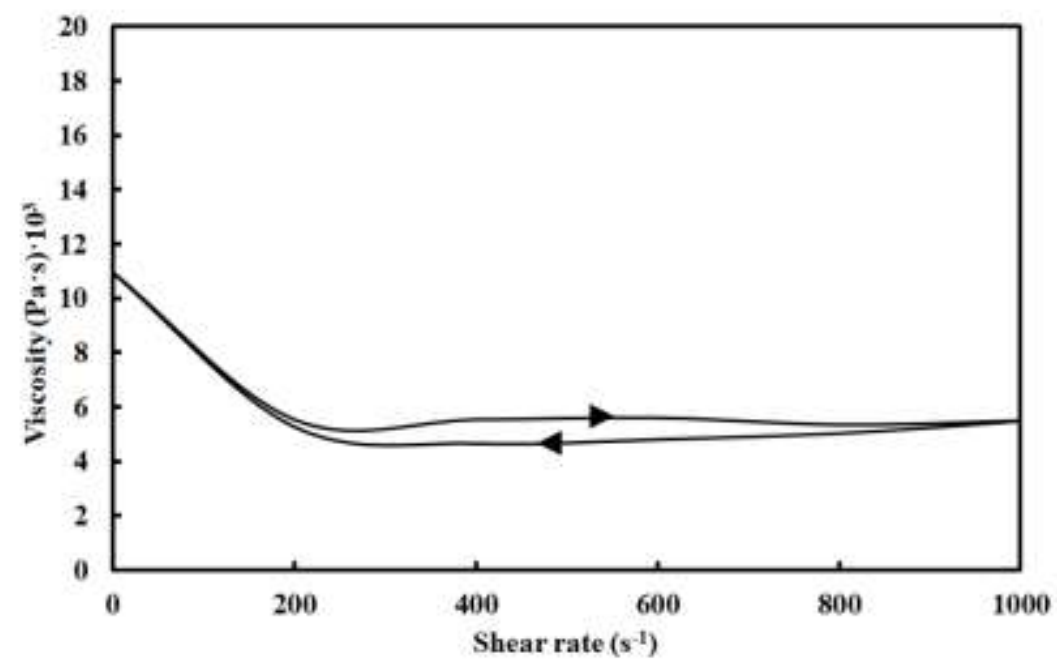

Figure 1 

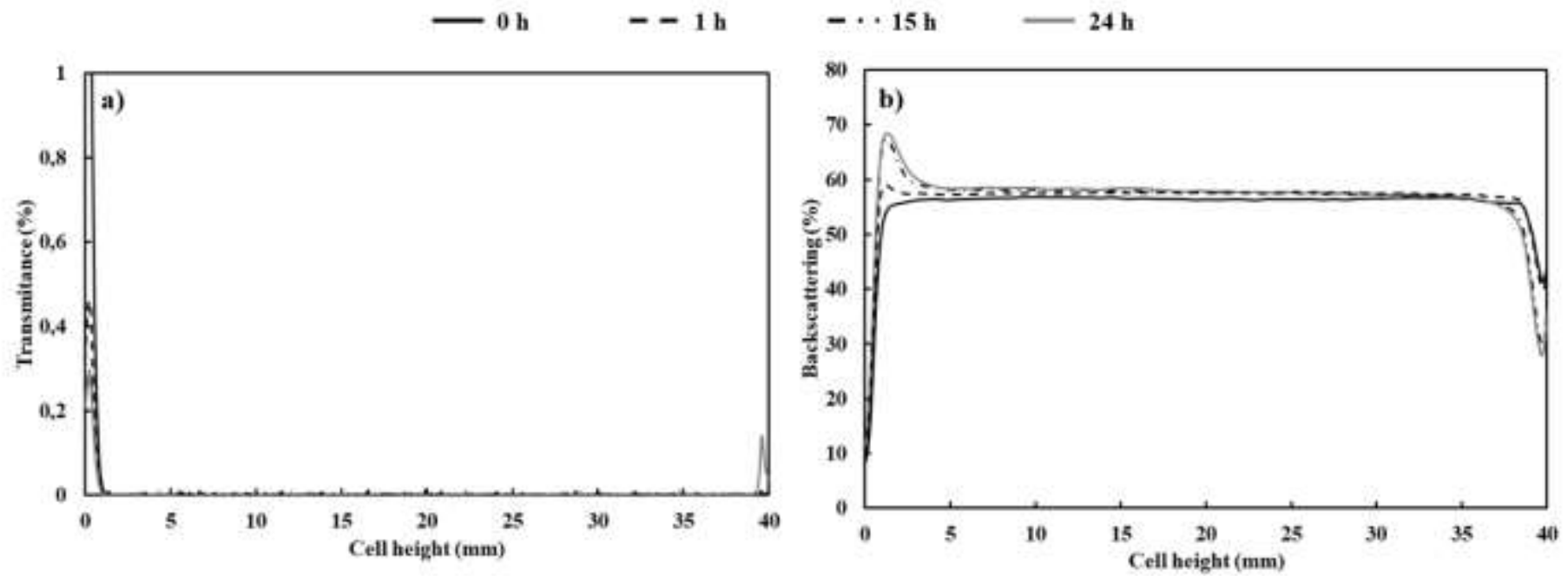

Figure 2 

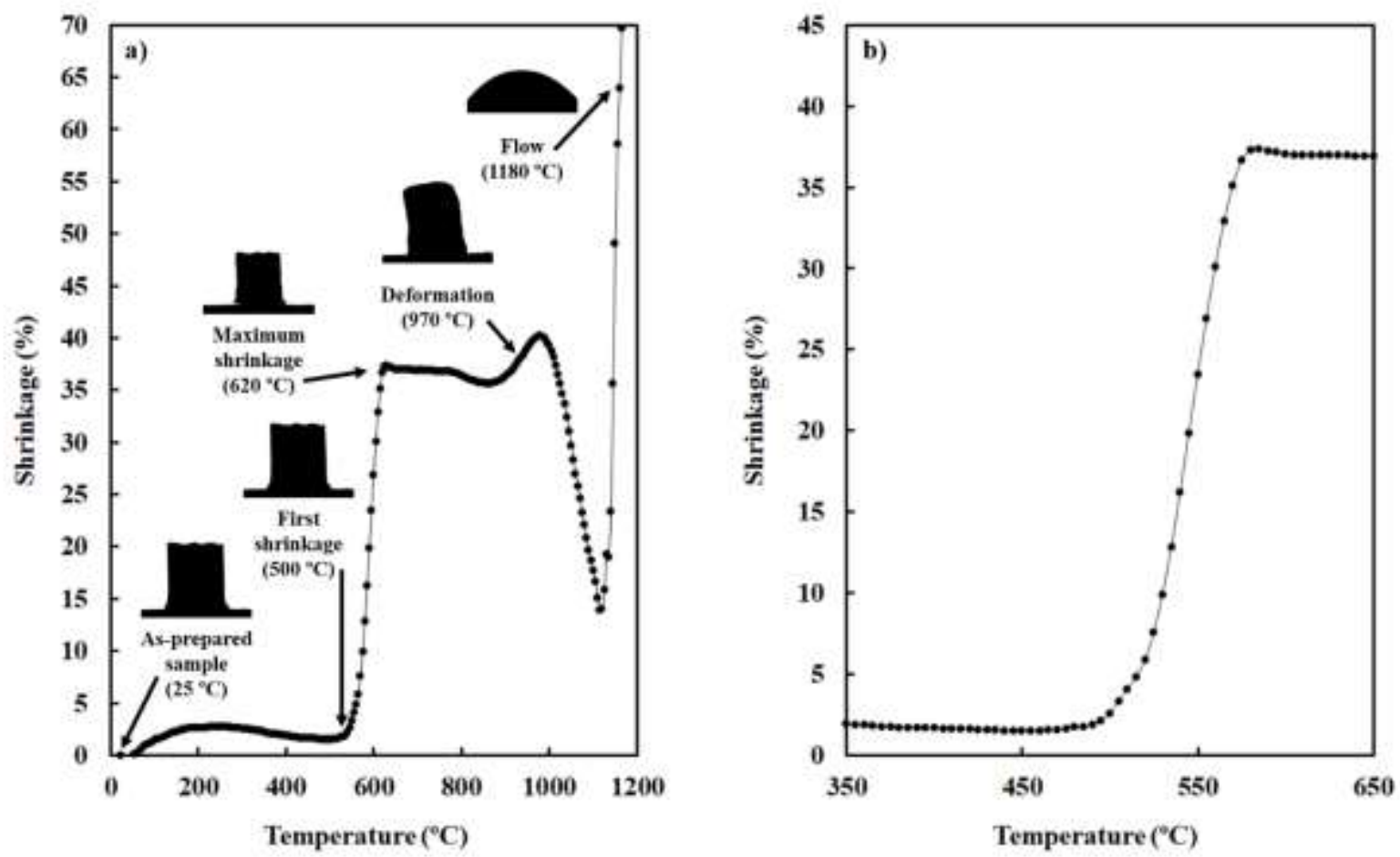

Figure 3 

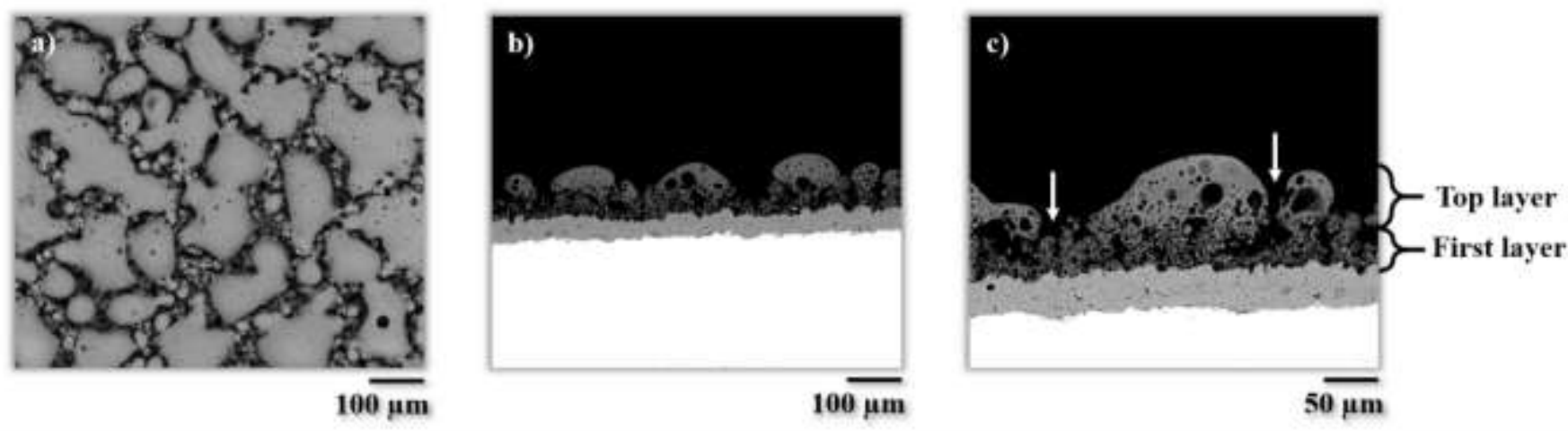

Figure 4 

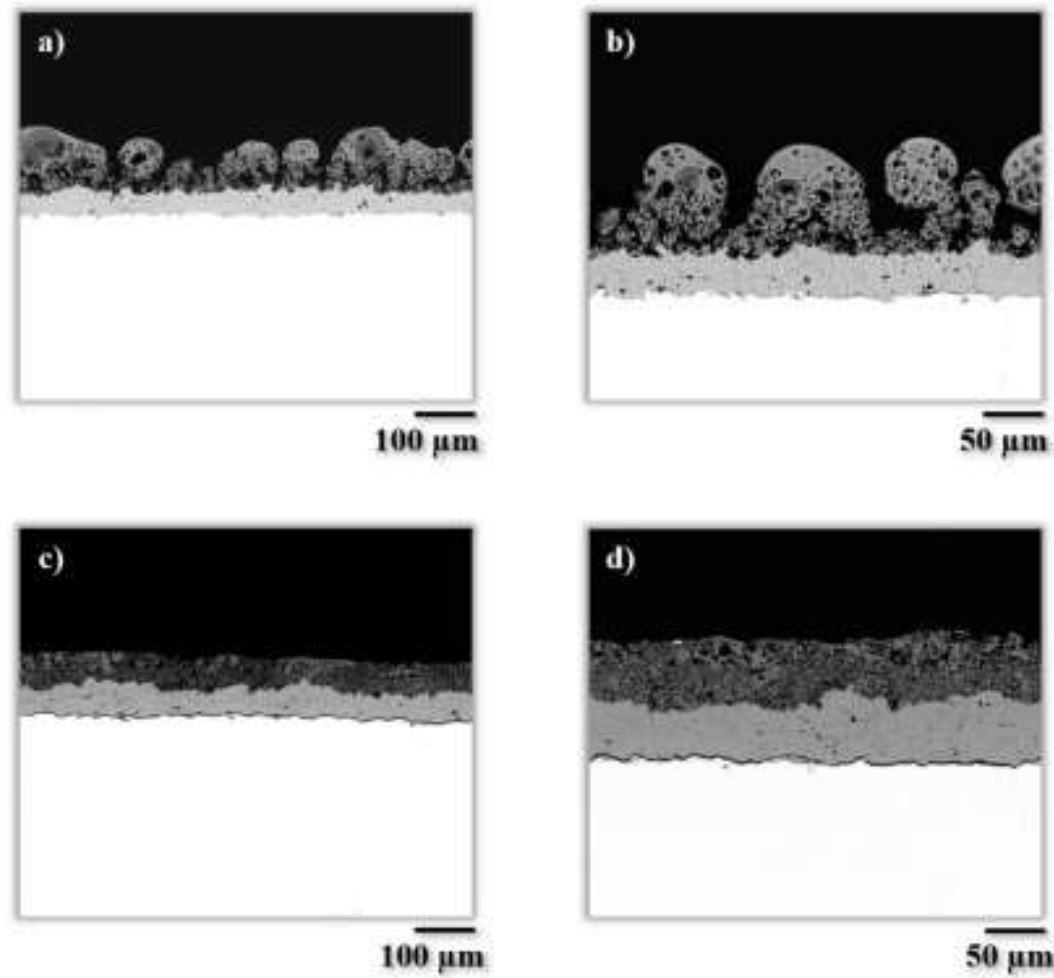

Figure 5 


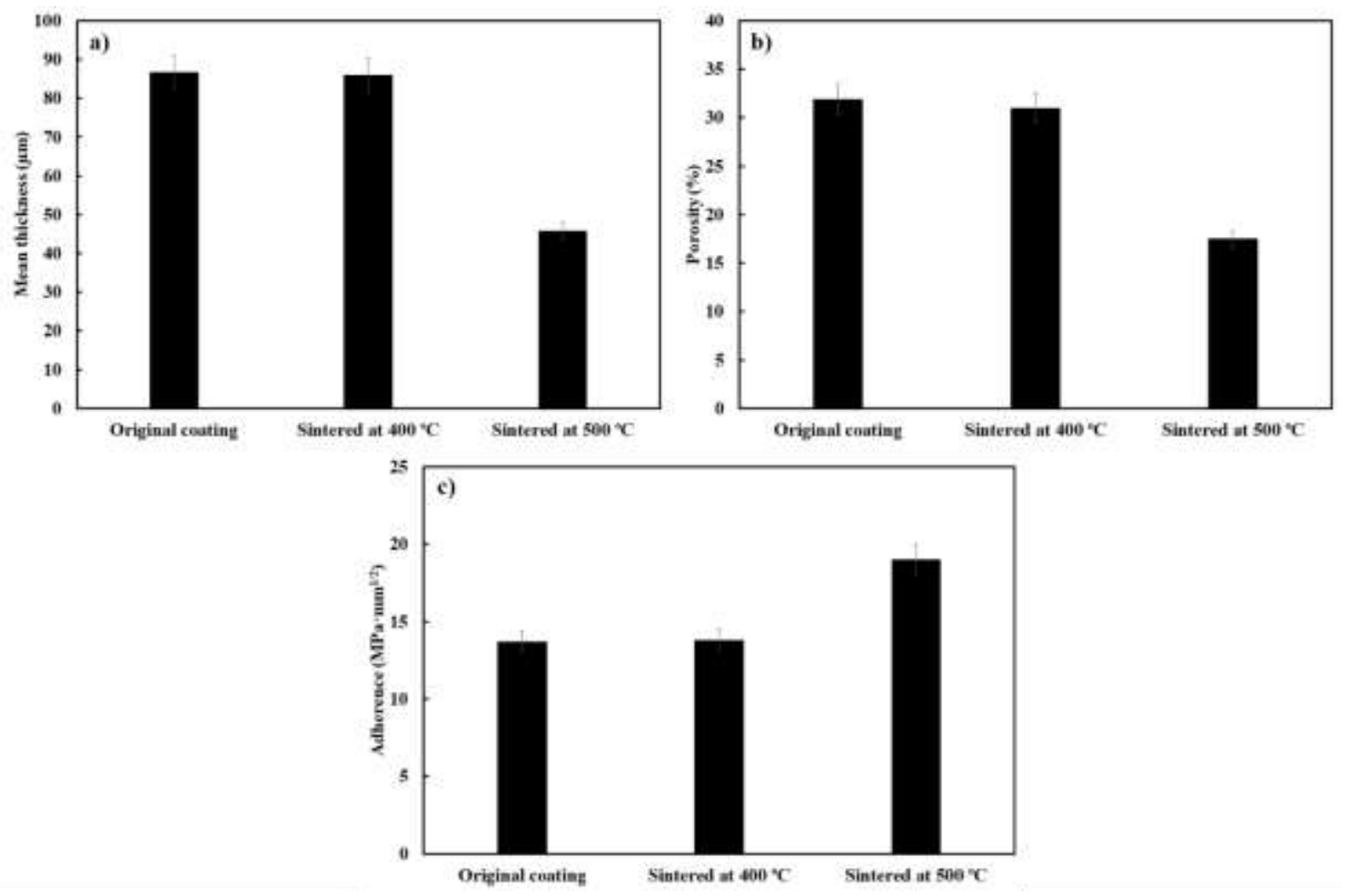

Figure 6 

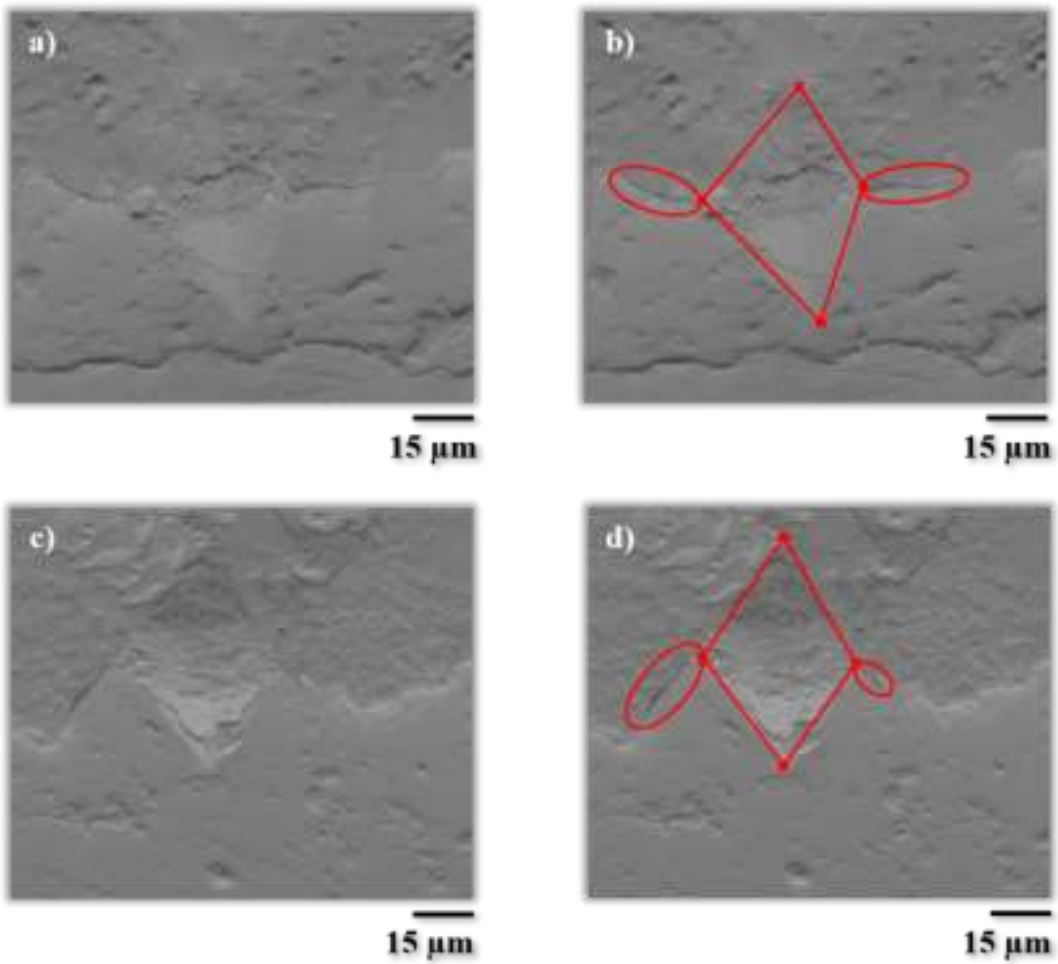

Figure 7 


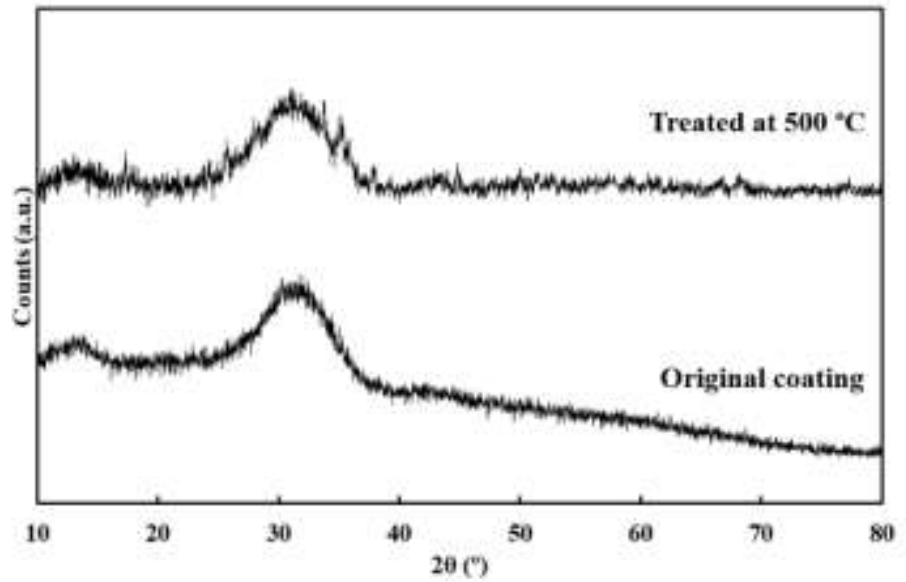

Figure 8 